\title{
Modeling Deep Decarbonization: Robust Energy Policy and Climate Action
}

\author{
Hongbo Duan ${ }^{1}$, Joeri Rogelj ${ }^{2,3}$, Jason Veysey ${ }^{4}$, Shouyang Wang ${ }^{1,5}$ \\ 1. School of Economics \& Management, University of Chinese Academy of Sciences, Beijing \\ 100190, China, \\ 2. Grantham Institute for Climate Change and the Environment, Imperial College London, London \\ SW7 2AZ, UK, \\ 3. International Institute for Applied Systems Analysis (IIASA), A-2361 Laxenburg, Austria \\ 4. Stockholm Environment Institute, 11 Curtis Avenue, Somerville, MA 02144, United States \\ 5. Academy of Mathematics and Systems Science, Chinese Academy of Sciences, Beijing \\ 100190, China
}

\section{Introduction}

The accumulating greenhouse gases (GHGs) in the Earth's atmosphere are heating the Earth's surface [1]. In 2018, the IPCC released its Special Report on global warming of $1.5^{\circ} \mathrm{C}$ (SR15), suggesting that the global average temperature is likely to reach $1.5^{\circ} \mathrm{C}$ above pre-industrial levels between 2030 and 2052, at the present rate of warming [2]. Given that the time available for international cooperation in reducing carbon emissions is dismally running out, and current national commitments on GHG emissions fall well short of the goals laid out in the Paris climate agreement, the public may rightly be concerned that even the $2{ }^{\circ} \mathrm{C}$ target is slipping out of reach [3]. It is therefore of great urgency and importance to determine how to decelerate the warming trend and prevent the socioeconomic system from suffering irreversible climate damage [4].

The increasingly serious situation of global warming necessitates deep decarbonization in our economy. Attaining this goal requires effective policy design at all levels, particularly to address externalities and other market failures that are contributing to climate degradation. Model-based integrated analysis can play a critical role in envisioning and testing effective decarbonization policies. Credible approaches include feasible least-cost pathways, quantification of multiple uncertainties, and consideration of difficult to model but crucial factors such as innovation processes, business strategies, and political struggles [5]. Since the historical record shows that carbon emissions are have been highly related to economic development in most countries, the compatibility of decarbonization and economic performance is a central question.

Analyses must moreover account for the interplay among policies. An overall carbon pricing policy might be preferred for decarbonization on grounds of efficiency, but a combination of policies can have a superior effect. Models should be able to examine both cases and evaluate the impacts of existing policies in various future scenarios. Another key issue is how to represent dynamics at sectoral and regional levels, particularly with regard to energy restructuring. As a whole, achieving deep decarbonization is a complicated issue that involves economics, politics, technology and finance, implicating active interaction and deep integration of different domains.

To contribute to deep decarbonization through the ongoing policy-oriented research, this special issue sought to compile, interrelate, and highlight studies that can shed light on key issues in future energy and economic decarbonization, also in the hopes of bringing new inspiration to its readers and to society at large. Having received over 80 submissions, this special issue accepts 14 papers in total, focusing on several subtopics relevant to decarbonization, including the feasibility of decarbonization, policy design and decision making, decomposition and decoupling for mitigation analysis, the role of technological progress, and energy restructuring and transformation. The authors in this special issue come from 45 institutions in 9 countries; more than half of these institutions are from China, three come from Australia, two from the US, with the remaining eleven institutions coming from six countries in Europe. 


\section{Deep decarbonization, given the $1.5^{\circ} \mathrm{C}$ or $2^{\circ} \mathrm{C}$ target}

The first set of papers in this special issue model or assess the feasibility of decarbonization under the premise of the $1.5^{\circ} \mathrm{C}$ or $2{ }^{\circ} \mathrm{C}$ target. Marcucci et al. [6] conducted a probabilistic assessment of the energy transition and economic consequences by limiting global warming by the end of this century to $1.5^{\circ} \mathrm{C}$. The assessment was developed based on a technology-enriched integrated assessment model MERGE-ETL. To address uncertainties resulting from multiple factors-such as economic growth, technology cost and resources endowment-the authors created distributions for these variables by applying the PROMETHEUS model, and exploited Monte Carlo analysis in the assessment. The results show that achieving the $1.5^{\circ} \mathrm{C}$ target is technically feasible, but requires immediate and global action. Specifically, key factors in the decarbonization of the energy system are: large-scale deployment of renewable energy, early retirement of fossil-based power plants, energy efficiency enhancements, and negative emission technologies.

The industrial sector is responsible for about one quarter of global carbon emissions. Progress toward mitigating these emissions varies widely around the world, as different regions are at different industrialization stages, and have different energy systems and constrains. Wang and Chen [7] explored the possible transitions in the industrial sector under the $2^{\circ} \mathrm{C}$ target for China, India, and Western Europe respectively. By introducing Shared Socio-economic Pathways into the energy system model Global TIMES, a comparison between the three regions was conducted. The results reveal that regional differences in energy structure may greatly explain the differences in future energy structure transitions across regions, particularly under the given climate goals. However, for some regions, such as China, the decarbonization differences between the specific country and the world are expected to be narrowed, due to a faster reduction rate of emissions.

\section{Decomposition and decoupling analysis}

It's widely believed that economic growth is the main factor driving the increase of $\mathrm{CO}_{2}$ emissions; there should be many other factors that also play important roles in the differing patterns of $\mathrm{CO}_{2}$ emissions across regions. A better understanding of such key driving factors, and the possible relationship between economic growth and $\mathrm{CO}_{2}$ emissions, would be of great value to deep decarbonization policymaking in all countries. By combining a production-theoretical decomposition analysis (PDA) and index decomposition analysis (IDA), Liu et al. [8] decomposed the changes in China's carbon emissions during the 2007-2016 period in terms of 9 primary driving factors, concluding that economic activity was the dominant emission contributor for all regions in China, while carbon efficiency and potential carbon productivity also played formidable-important roles. Conversely, energy intensity, the catch-up effect of pure technical efficiency, and scale efficiency in carbon emissions contributed positively to reduce carbon emissions. From a production technology perspective, Fan et al. [9] employed PDA to decompose the changes in $\mathrm{CO}_{2}$ emissions across the "Belt and Road Initiatives (BRI)" countries from 2000 to 2014 according to 7 typical driving factors. The results support the main finding of Liu et al. [8], that is, that economic growth and emission inertia dominated the increase of $\mathrm{CO}_{2}$ emissions in the past decade. In contrast, improvements in carbon abatement technology and energy intensity potentials played an inhibiting role in the growth of emissions. Specifically, this research finds that most BRI countries (except China) feature a similar technology-side carbon abatement effect efficiency, whereas larger fluctuations are observable in China.

Based on the panel data from 2001 to 2015, Chen et al. [10] applied the Logarithmic Mean Division Index (LMDI) method to decompose the $\mathrm{CO}_{2}$ emissions of the Organization for Economic Co-operation and Development (OECD) countries in terms of 6 impact factors; the relationship between such factors and $\mathrm{CO}_{2}$ emissions in all target countries was also examined, using Tapio decoupling analysis. Moreover, the LMDI was embedded into the decoupling analysis to explore the influences of technical and non-technical factors on the decoupling elasticity. As indicated by the results, energy intensity and GDP per capita were the main contributors to $\mathrm{CO}_{2}$ emissions, with a negative effect and a positive effect, respectively. Further, the role of technical factors was found to be more significant than that of non-technical factors, given the opposite directions of influence. Considering a similar time period, the decoupling relationship between $\mathrm{CO}_{2}$ emissions and 
economic development was also evaluated in Li et al. [11], targeting China's 30 Central Plains cities, and using the Tapio elastic analysis method. The results indicated that 5 cities showed strong decoupling effects after 2010, 13 cities showed weak decoupling, 4 cities presented growth connection, and 7 cities presented growth negative decoupling. The different decoupling patterns in these cities imply that it may be difficult for some cities to significantly reduce their $\mathrm{CO}_{2}$ emissions in the short term, particularly due to the strong inertia of the current energy structure.

\section{Renewables and sector-level mitigation strategies}

The power sector accounts for an overwhelming proportion of worldwide carbon emissions, which greatly underscores the importance of a high penetration of renewables in electricity systems, such as wind, solar PV and hydropower-in energy systems in order to achieve deep decarbonization [12-13]. Generally, new technologies can provide powerful momentum for rapid and deep reductions in carbon emissions, and even niche innovations are able to accelerate decarbonization in particular regions or niche sectors [14]. Liu et al. [15] developed a 31-node hourly-resolved techno-economic optimization model to investigate future scenarios of renewable energy penetration for the Chinese power system. The model was supported by a valid long-term and highresolution dataset to secure the optimal system configuration. This paper also compared the feasibility of attaining near-zero emissions for three different grid scenarios, and explored the roles of reservoir hydro and storage. Decarbonization of the power sector also relies on the attainment of grid parity for renewables (e.g. wind), which in turn depends on the effects of carbon pricing, as well as technological learning and non-technical curtailments [16]. In general, carbon pricing could accelerate grid parity, whereas a high discount rates, low learning rates, high curtailment rates, high O\&M cost, and low capacity factors may delay grid parity.

Restructuring of the building and transportation sectors is also an important aspect of deep decarbonization, involving economic feasibility analysis, mitigation potential assessment, and technological change. Targeting four Swedish cities, Mata et al. [17] developed five climate change scenarios to examine the roles of multiple uncertainties-including climate sensitivity, the boundaries for emission inventories, and energy system development—on assessment of economic feasibility and mitigation potentials of building retrofits. The results show that the profitability of retrofitting actions is primarily determined by annualized investments and energy saving potentials, whereas the role of future climate change is less dominant. As a consequence, attention to strategies for building retrofits and should prioritize energy savings and mobilizing investments that may not be profitable based on the current techno-economic perspective. On the contrary, technological change and shifts in customer behavior may play significant roles in energy restructuring and decarbonization of the transportation sector. By proposing a mixed-integer (0-1 linear) green routing model and developing a genetic algorithm, Chiang et al. [18] assessed the sustainability potential of drone delivery. The computational results show that when drones and vehicles are jointly used to deliver parcels, drones can help to save fixed costs by reducing the total delivery time and the number of vehicles required, which in other words could largely reduce energy usage and relative carbon emissions.

\section{Policy effectiveness evaluation}

As climate change involves global externalities; effective policy design is therefore indispensable to correct market failures. An inappropriate policy intervention could be ineffective, or even worse, could exacerbate market distortions, which means the impacts of relevant policies should be carefully and comprehensively evaluated, before and after their implementation. By using the panel data of 114 cities from the period of 2005-2016, Lin and Zhu [19] employed the non-directional distance function method and constructed a sustainability indicator to evaluate the effect of the "National Comprehensive Demonstration of Energy Saving and Emission Reduction Fiscal Policy" (ESER policy) on China's eco-efficiency; this study indicated that the ESER policy had a positive and statistically significant effect on eco-efficiency, but this effect would only emerge three years post its enforcement. Yi, Xu, and Fan [20] evaluated the effects of two policies on China's power sector by combining a multi-regional power optimization model with a decomposition method. The results reveal that these two policies have overlapping effects on some levels, despite very different 
influences on the future evolution pathways of China's power supply system. This emphasizes the great importance of coordinating goals of different policies.

Emodi, Chaiechi, and Beg [21] applied the concept of combining backcasting and exploratory scenarios to examine the policy effectiveness of potential emission reductions for the Australian electricity sector. The concept was actualized by combining the energy system simulation model LEAP and the optimization model OSeMOSYS; two climate change scenarios-RCP4.5 and RCP 8.5-were considered in the evaluation. The simulation results identified three least-cost generation expansion options with effective emission reduction policies. Economic analysis showed that emission reduction policy will result in an extra cost to the economy, while carbon tax policies will yield various economic benefits. Zhang et al. [22] developed a model for solving investment decisions in the low-carbon transition toward renewables. The model empirically evaluated the optimal strategy for the transition investment from a coal-fired power plant to a solar PV power plant in China, by incorporating various sources of uncertainty and considering the situations with and without a carbon emission trading scheme (ETS). They reported some policy insights: on the one hand, the government should optimize its policy design so as to scientifically address uncertainties and guide investor decisions on low-carbon transitions; on the other hand, the government needs to maintain the stability of both the carbon trading market and fossil fuel market, or incentivized policy effects will be greatly reduced, and the government's financial burden and risk would be significantly increased.

\section{Concluding remarks}

Deep decarbonization is a complex and systemic process, requiring an interlinked mix of technologies, infrastructures, organizations, markets, policies, and user practices [3]. At present, it poses a large number of significant open issues. We hope that the papers in this special issue provide to relevant readers with new and relevant insights on these questions, and identify new directions for future research. Undoubtedly, rapid and deep decarbonization is still facing enormous challenges. More cross-model and policy analysis are required to provide solid and scientific evidence [23]; we believe that this special issue is a good step in that direction.

\section{Acknowledgements}

The Guest Editors are grateful for a group of outstanding and dedicated peer reviewers who collaborated with us in the evaluation of submissions to this special issue. This work is financially supported by the National Natural Science Foundation of China (NSFC, Nos. 71874177; 71690245; 71988101).

\section{References}

[1] Oreskes N. The Scientific Consensus on Climate Change. Science (80- ) 2004;306:1686-1686. https://doi.org/10.1126/science.1103618.

[2] IPCC. Summary for Policymakers. Global Warming of $1.5^{\circ} \mathrm{C}$. An IPCC Special Report on the impacts of global warming of $1.5{ }^{\circ} \mathrm{C}$ above pre-industrial levels. 2018. https://doi.org/10.1017/CBO9781107415324.

[3] Rogelj J, Luderer G, Pietzcker RC, Kriegler E, Schaeffer M, Krey V, et al. Energy system transformations for limiting end-of-century warming to below $1.5^{\circ} \mathrm{C}$. Nat Clim Chang 2015;5:519-27. https://doi.org/10.1038/nclimate2572.

[4] Duan H, Zhang G, Wang S, Fan Y. Robust climate change research: A review on multi-model analysis. Environ Res Lett 2019;14. https://doi.org/10.1088/1748-9326/aaf8f9.

[5] Rockström J, Gaffney O, Rogelj J, Meinshausen M, Nakicenovic N, Schellnhuber HJ. A roadmap for rapid decarbonization. Science (80- ) 2017;355:1269-71. https://doi.org/10.1126/science.aah3443.

[6] Marcucci A, Panos E, Kypreos S, Fragkos P. Probabilistic assessment of realizing the $1.5^{\circ} \mathrm{C}$ climate target. Appl Energy 2019:239-51. https://doi.org/10.1016/j.apenergy.2019.01.190.

[7] Wang H, Chen W. Modelling deep decarbonization of industrial energy consumption under 2degree target: Comparing China, India and Western Europe. Appl Energy 2019;238:1563-72. https://doi.org/10.1016/j.apenergy.2019.01.131. 
[8] Liu B, Shi J, Wang H, Su X, Zhou P. Driving factors of carbon emissions in China: A joint decomposition approach based on meta-frontier. Appl Energy 2019;256:113986. https://doi.org/10.1016/j.apenergy.2019.113986.

[9] Fan JL, Da Y Bin, Wan SL, Zhang M, Cao Z, Wang Y, et al. Determinants of carbon emissions in 'Belt and Road initiative' countries: A production technology perspective. Appl Energy 2019;239:268-79. https://doi.org/10.1016/j.apenergy.2019.01.201.

[10] Chen J, Wang P, Cui L, Huang S, Song M. Decomposition and decoupling analysis of CO 2 emissions in OECD. Appl Energy 2018;231:937-50. https://doi.org/10.1016/j.apenergy.2018.09.179.

[11] Li L, Shan Y, Lei Y, Wu S, Yu X, Lin X, et al. Decoupling of economic growth and emissions in China's cities: A case study of the Central Plains urban agglomeration. Appl Energy 2019;244:36-45. https://doi.org/10.1016/j.apenergy.2019.03.192.

[12] Veysey J, Octaviano C, Calvin K, Martinez SH, Kitous A, McFarland J, et al. Pathways to Mexico’s climate change mitigation targets: A multi-model analysis. Energy Econ 2014;56:58799. https://doi.org/10.1016/j.eneco.2015.04.011.

[13] Du Y, Song B, Duan H, Tsvetanov TG, Wu Y. Multi-renewable management: Interactions between wind and solar within uncertain technology ecological system. Energy Conversion and Management 2019; 187: 232-247. https://doi.org/10.1016/j.enconman.2019.01.032

[14] Duan H, Zhang G, Wang S, Fan Y. Integrated benefit-cost analysis of China's optimal adaptation and targeted mitigation. Ecol Econ 2019;160:76-86. https://doi.org/10.1016/j.ecolecon.2019.02.008.

[15] Liu H, Brown T, Andresen GB, Schlachtberger DP, Greiner M. The role of hydro power, storage and transmission in the decarbonization of the Chinese power system. Appl Energy 2019;239:1308-21. https://doi.org/10.1016/j.apenergy.2019.02.009.

[16] Tu Q, Betz R, Mo J, Fan Y, Liu Y. Achieving grid parity of wind power in China - Present levelized cost of electricity and future evolution. Appl Energy 2019;250:1053-64. https://doi.org/10.1016/j.apenergy.2019.05.039.

[17] Mata É, Wanemark J, Nik VM, Sasic Kalagasidis A. Economic feasibility of building retrofitting mitigation potentials: Climate change uncertainties for Swedish cities. Appl Energy 2019;242:1022-35. https://doi.org/10.1016/j.apenergy.2019.03.042.

[18] Chiang WC, Li Y, Shang J, Urban TL. Impact of drone delivery on sustainability and cost: Realizing the UAV potential through vehicle routing optimization. Appl Energy 2019;242:116475. https://doi.org/10.1016/j.apenergy.2019.03.117.

[19] Lin B, Zhu J. Impact of energy saving and emission reduction policy on urban sustainable development: Empirical evidence from China. Appl Energy 2019;239:12-22. https://doi.org/10.1016/j.apenergy.2019.01.166.

[20] Yi BW, Xu JH, Fan Y. Coordination of policy goals between renewable portfolio standards and carbon caps: A quantitative assessment in China. Appl Energy 2019;237:25-35. https://doi.org/10.1016/j.apenergy.2018.12.015.

[21] Emodi NV, Chaiechi T, Alam Beg ABMR. Are emission reduction policies effective under climate change conditions? A backcasting and exploratory scenario approach using the LEAPOSeMOSYS Model. Appl 2019;236:1183-217. https://doi.org/10.1016/j.apenergy.2018.12.045.

[22] Zhang MM, Wang Q, Zhou D, Ding H. Evaluating uncertain investment decisions in low-carbon transition toward renewable energy. Appl Energy 2019;240:1049-60. https://doi.org/10.1016/j.apenergy.2019.01.205.

[23] Nordhaus WD. Revisiting the social cost of carbon. Proc Natl Acad Sci U S A 2017;114:151823. https://doi.org/10.1073/pnas.1609244114. 